\title{
A Systems-Centric, Foundational Experience in Circuits
}

\section{Dr. Tom Weller, University of South Florida}

Thomas M. Weller received the B.S., M.S. and Ph.D. degrees in Electrical Engineering in 1988, 1991, and 1995, respectively, from the University of Michigan, Ann Arbor. From 1988-1990 he worked at Hughes Aircraft Company in El Segundo, CA. He joined the University of South Florida in 1995 where he is currently professor and chair in the Electrical Engineering Department.

\section{Dr. Carol M. Haden, Magnolia Consulting, LLC}

Carol Haden holds a doctorate in Curriculum and Instruction from Northern Arizona University, with an emphasis in program evaluation. She specializes in the evaluation of programs in STEM education across the K-20 spectrum and the evaluation of STEM Education and Public Outreach programs. Carol has designed and conducted evaluations of projects sponsored by the National Science Foundation, the William and Flora Hewlett Foundation, NASA, the Arizona Board of Regents, Goddard Space Flight Center, Jet Propulsion Laboratory and the Arizona Department of Education, among others.

\section{Dr. Jeff Frolik, University of Vermont \\ Dr. Paul G. Flikkema, Northern Arizona University \\ Dr. Aaron T. Ohta, University of Hawaii at Manoa}

Dr. Aaron Ohta received a B.S. from the University of Hawaii at Manoa in 2003, an M.S. from the University of California, Los Angeles in 2004, and a Ph.D. from the University of California, Berkeley in 2008, all in the field of electrical engineering. He is currently an Associate Professor of Electrical Engineering at the University of Hawaii at Manoa, where he has been since 2009. Dr. Ohta's research interests include microelectromechanical systems (MEMS) and microfluidics. He has published two book chapters and over 70 peer-reviewed journal and conference papers, and is co-inventor on 2 U.S. patents.

\section{Dr. Sylvia W. Thomas, University of South Florida}

Dr. Sylvia Wilson Thomas is currently an Assistant Professor in Electrical Engineering and former Assistant Dean for the College of Engineering at the University of South Florida in Tampa, Florida. She holds several patents and has over twenty-five years of experience in industry and academia.

Research Interests

Sylvia Wilson Thomas, Ph.D. leads the Advanced Materials Bio and Integration Research (AMBIR) laboratory at USF. Dr. Thomas' research and teaching endeavors are focused on advanced materials for alternative energy sources, sustainable environments, aerospace, and bio-applications from the micro to the nano scale. Her research investigates the fabrication of inorganic and organic thin films and nanofibers for device integration. Thomas' research group specializes in characterizing, modeling, and integrating materials that demonstrate high levels of biocompatibility, thermal reflectivity, mechanical robustness, and environmental sustainability, such as carbides, sol-gel coatings, high temperature oxides, and several polymers. Her research is interdisciplinary in nature and fosters collaborations with Chemical and Biomedical, Mechanical, and Environmental Engineering, Physics, Chemistry, Public Health, Medicine, and the Nanotechnology Research and Education Center (NREC).

\section{Prof. Rhonda R. Franklin, University of Minnesota}

Rhonda Franklin (S'84-M'96) received the B.S. degree in electrical engineering from Texas A\&M University, College Station, TX and M.S. and Ph.D. degree in electrical engineering from The University of Michigan, Ann Arbor, MI in 1990 and 1995, respectively.

She is currently a Professor with Electrical and Computer Engineering department at the University of Minnesota. Her research interests include RF/microwave passive circuit design, interconnects and integration techniques using MEMS and other advanced fabrication processes, RF fluidics, and high speed 
material's characterization. Her engineering education interests are in systems thinking, integrated learning, and active learning. She has authored or co-authored over 85 professional journals and conference publications and 4 book chapters.

Dr. Franklin was the recipient of the 1998 Presidential Career Award for Scientists and Engineers by the National Science Foundation. She is an active member of the MTT-S society in the technical area of passives, packaging, integration and microwave education and is currently an Associate Editor of the IEEE Microwave Wireless Components Letters.

\section{Dr. Wayne A. Shiroma, University of Hawaii at Manoa}




\section{A Systems-Centric, Foundational Experience in Circuits}

\section{Introduction}

Electrical and computer engineering (ECE) has been a driving force in the development of modern infrastructure, based on advances across a range of ECE sub-disciplines including electronics, communications, computing, and power. In recent decades, ECE has evolved well beyond a core of electrical and electronic hardware to become a broader field of innovation, including information creation, synthesis, transport, and analysis.

There is growing awareness that engineering, including ECE, must continue evolving in order to tackle important challenges facing humanity and the planet. These challenges include providing high-quality and affordable healthcare to an aging population, making better use of and diversifying our energy sources, and managing the environment for sustainability; all requiring new problem-solving skills to create the technological advances that will preserve our well-being, ensure our national security and maintain our leadership in the global economy ${ }^{1}$.

Solutions to $21^{\text {st }}$-century challenges will involve electronic systems intertwined with structural, chemical, and biological systems. One example, advances in nano- and nanobioengineering, will integrate knowledge from information, electrical, physical, cognitive and social sciences. The solutions are thus inherently multi-disciplinary-involving one or more disciplines with similar approaches to problem solving - and trans-disciplinary - involving two or more disciplines that may approach problem solving in dramatically different ways ${ }^{234}$. There is a broad consensus, most prominently noted in the National Academy of Engineering's The Engineer of $2020^{5}$, that tomorrow's engineers must be adept at new problem-solving approaches to successfully meet the challenges presented to our society and that current educational approaches are not sufficient.

The evolution of ECE education from physics and applied physics to electrical, electronic, and computer engineering was necessary for developing today's technology. Our $20^{\text {th }}$ century infrastructure, co-developed with ECE curricula dominated by a bottom-up approach to learning, and exemplified by a dominant focus on lumped linear elements, is typically presented in the absence of context of meaningful, motivating applications. More than a decade into the $21^{\text {st }}$ century, we now recognize the need and importance of systems-centric engineering approaches and that systems-thinking skills need to be integrated into the educational process in order to identify technological solutions for non-traditional application areas and/or nontraditional physical systems (e.g., the human body).

Educating tomorrow's engineers must involve the incorporation of research-based best practices in teaching and learning that are centered on an understanding of how students learn. Effective instruction should stimulate critical thinking through a variety of instructional strategies, including inquiry-based approaches, problem-solving opportunities, and opportunities for information gathering ${ }^{6}$. Providing "challenge-based learning experiences" that are anchored in data and tied to context-rich real-world topics increases the likelihood of deep learning ${ }^{7}$. Such opportunities allow students to use what they learn and to transfer this experience to new situations ${ }^{8}$. Additionally, students are motivated to learn subjects that are applicable to contemporary life and that connect to their interests and strengths. 
Guided by new problems and these educational principles, the project described in this paper has developed a systems-centric educational model that addresses the role of electrical engineering solutions in broader contexts. This project is a collaboration of five institutions: University of South Florida (USF), Northern Arizona University (NAU), University of Hawaii (UH), University of Vermont (UVM) and University of Minnesota (UMN).

\section{Background}

An introductory course in electrical circuits (hereafter referred to as Circuits) is typically one of the first discipline-specific courses found in ECE programs. Furthermore, Circuits is often a required course for non-ECE majors. Circuits tends to be focused almost solely on circuit analysis with little emphasis on design or applications. A typical course first addresses fundamental components and laws (resistors, capacitors and inductors, Ohm's and Kirchoff's laws) and proceeds to analysis methods (mesh and nodal analysis, DC and transient analysis). Depending on the institution and whether the course is for ECE majors, the course may conclude with a variety of topics including AC analysis, operational amplifiers, transformers, or digital electronics. While these topics are fundamental to the study of ECE, the approaches currently used to teach Circuits do not adequately address their place in larger systems and/or applications.

At some institutions, non-majors take Circuits along with ECE students as part of a multi-disciplinary core. At other institutions, a separate Circuits for Non-Majors course is offered for non-ECE students. In either case, non-majors often question the need for Circuits since they do not immediately see the relevance to their chosen major ${ }^{9}$. To make matters worse, that relevance may not even be seen (or discovered) during a student's entire program of study. Yet practicing engineers from all disciplines need a solid foundation in circuit concepts to effectively design, test, and manufacture modern systems for biomedical, civil, environmental, and mechanical applications.

Regardless of whether the course targets ECE majors, other engineering majors, or both, student questioning of the relevance of Circuits knowledge is of great concern when engineering is becoming ever more interdisciplinary. While evidence of this as an effect is often indirect or anecdotal, we note that Circuits is normally among the courses with the lowest quantitative student success rates, as indicated by our own Institutions' DFW (D/F grade and withdrawal) percentages (Table 1).

The inclusion and degree of experiential learning in Circuits varies by institution. Even at schools where a laboratory course accompanies the lecture course, the laboratory assignments tend to be straightforward demonstrations of the basic circuit principles discussed in the lectures. In our view, this approach cultivates the learning of little more than commodity skills. Moreover, it is generally viewed that the ability of U.S. graduates to successfully compete in our global society depends on them possessing a broad, interconnected knowledge base. Integrating realworld problems into Circuits can improve the learning of basic principles ${ }^{678}$. A recent study ${ }^{10}$ that compared an introductory physics course taught with and without experiential instruction found that the latter approach resulted in twice the learning even when more experienced instructors delivered the course using the traditional format.

The Engaging Fundamentals and Systems Engineering (ENFUSE) Project, discussed herein, involves the five noted institutions which are geographically and demographically 
diverse. The diversity of the partnering programs - residential and commuter, large and small, courses based on different formats (lecture, lab, and recitation) - has provided us with an excellent venue to understand the unique educational challenges and processes of different institutions. This project integrates learning of circuits and systems concepts, forming a new set of conceptual cornerstones for Circuits students. We have framed circuit concepts in three timely application areas and have developed materials that are readily adapted to a variety of courses/institutions.

Table 1 - Institutional Data for Circuits

\begin{tabular}{|c|c|c|c|c|c|c|}
\hline University & Course & $\begin{array}{l}\text { Credit } \\
\text { Hours }\end{array}$ & Major & $\begin{array}{c}\text { Yearly } \\
\text { Enrollment }\end{array}$ & $\begin{array}{l}\text { DFW } \\
\text { Rate }\end{array}$ & Comments \\
\hline USF & $\begin{array}{l}\text { EGN } \\
3373\end{array}$ & 3 & EE \& Non-EE & 495 & $34.1 \%$ & Lecture \\
\hline \multirow{2}{*}{ NAU } & EE 188 & 3 & $\begin{array}{c}\text { EE, ME, CE, } \\
\text { EnvE }\end{array}$ & 260 & $30.0 \%$ & Lecture \\
\hline & EE 188L & 1 & $\begin{array}{c}\text { EE, ME, CE, } \\
\text { EnvE }\end{array}$ & 200 & $5.0 \%$ & $\mathrm{Lab}$ \\
\hline UH & EE 211 & 4 & ECE, ME, Pre-E & 160 & $28.9 \%$ & Integrated Lab \\
\hline \multirow{3}{*}{ UVM } & EE 3 & 3 & $\mathrm{EE}$ & 25 & $7.3 \%$ & Lecture \\
\hline & EE 81 & 2 & $\mathrm{EE}$ & 25 & $4.6 \%$ & $\mathrm{Lab}$ \\
\hline & EE 100 & 4 & ME, CE, EnvE & 120 & $10.2 \%$ & Integrated Lab \\
\hline \multirow{4}{*}{ UMN } & EE 2001 & 3 & $\mathrm{EE}$ & 179 & $18.6 \%$ & Lecture+Recitation \\
\hline & EE 2002 & 1 & $\mathrm{EE}$ & 158 & $14.1 \%$ & Lab \\
\hline & EE 3005 & 3 & ME, Aero & 293 & $8.1 \%$ & Lecture+Recitation \\
\hline & EE 3006 & 1 & ME, Aero & 264 & $3.7 \%$ & $\mathrm{Lab}$ \\
\hline
\end{tabular}

Table 2 - Theme-based Learning Modules for Circuits

\begin{tabular}{|c|c|c|c|}
\hline Thematic Area & Learning Module & Systems Concepts & Circuits Concepts \\
\hline Health & Bioelectrical Signals & $\begin{array}{l}\text { filtering, amplification, } \\
\text { models } \\
\text { measurement, detection; } \\
\text { health and safety }\end{array}$ & $\begin{array}{l}\text { resistors, capacitors, Ohm's } \\
\text { law, KCL, KVL, parallel } \\
\text { op amps } \\
\text { voltage, current, power, } \\
\text { AC analysis }\end{array}$ \\
\hline Energy & $\begin{array}{l}\text { Power measurement } \\
\text { DC-AC Inversion } \\
\text { Inductive Heating }\end{array}$ & $\begin{array}{l}\text { smart grid, real and reactive } \\
\text { power } \\
\text { renewable energy } \\
\text { energy use, energy } \\
\text { transformation }\end{array}$ & $\begin{array}{l}\text { resistors, inductors, } \\
\text { capacitors, transformers, } \\
\text { Ohm's law, voltage } \\
\text { division, power and energy, } \\
\text { AC power, RC circuits } \\
\text { resistivity, inductors, } \\
\text { electromagnetic fields, } \\
\text { Ohm's law }\end{array}$ \\
\hline Environment & $\begin{array}{l}\text { Remote Sensing } \\
\text { Environmental Sensing }\end{array}$ & $\begin{array}{l}\text { measurement, signal } \\
\text { conditioning, packaging } \\
\text { signal transduction, } \\
\text { modeling }\end{array}$ & $\begin{array}{l}\text { resistors, capacitors, AC } \\
\text { analysis } \\
\text { resistance, voltage division }\end{array}$ \\
\hline
\end{tabular}

Learning Materials

We have developed curricular material in portable, easily adopted Learning Modules. Seven learning modules have been created in three thematic areas: Health, Energy, and 
Environment. As illustrated in Table 2, using a particular theme, numerous concepts at the circuit level and the systems level are covered.

Our objective for developing this content was to improve student learning outcomes and lower barriers to adoption by faculty. Instructional videos complement experiential learning activities. The content leverages a slide deck that is annotated using the iPad application, Explain Everything. Both video and audio are captured, enabling asynchronous learning and a flipped classroom format.

Our previous work ${ }^{11}$ and that of others ${ }^{7,9}$ have demonstrated the value of hands-on learning. Hence we have developed experiential learning materials that complement the instructional content of each of the following Learning Modules.

Bioelectrical Signals and Systems (Health): In this module, students experiment with a pulse sensor and study the impact that varying the time constant of an RC filter has on the recorded pulse signal. Students use a commercial optical pulse sensor to measure their pulse rates with an oscilloscope, and construct a simple RC circuit to filter the pulse waveform. The accompanying instructional video covers examples of different types of bioelectrical signals and how their characteristics determine the requirements of the measuring instruments. The video also ties these topics to circuit concepts (resistors, capacitors and Ohm's law) and systems concepts (filtering, amplification and hierarchical circuit models).

Radiation from Wireless Devices (Health): In the experiential component of this module, students begin with a pre-lab group exercise analyzing the radiation safety hazard from a cell phone tower along an interstate highway. This motivates the connection between AC signal frequency and power, wireless propagation, and government guidelines for health and safety. In the experiment, students measure the level of leakage from a microwave oven, as compared to the radiation from their own cell phones. Greater depth can be obtained by discussing antennas as resonant circuits, distributed vs. lumped circuits, frequency-selective surfaces (such as the oven door), the molecular constitution of microwaveable food, and health and safety issues associated with microwave radiation.

$D C / A C$ Inversion (Energy): A timely topic is the integration of renewables into our electrical power system. This module motivates the study of circuit fundamentals using the topic of $\mathrm{DC} / \mathrm{AC}$ inversion, which is requisite for integrating photovoltaic solar panels into the grid. A key objective of this experiment is to introduce non-linear components - diodes, transistors, and flip-flops - that students may not have not used before. The experiential component integrates these components into a DC/AC inverter system, giving students a real-world example of the diversity of electronic circuits technologies and how they can be combined to create systems essential to modern life. In the videos, students are aided in the conceptual jump to the activelycontrolled transistor $\mathrm{H}$-bridge using diode-based half- and full-wave rectifier circuits. In the experimental procedure, students construct the three subsystems (clock source, control circuitry, and $\mathrm{H}$-bridge) of a simple DC/AC inversion circuit and then interconnect them. They monitor key waveforms to see the how the interplay of analog and digital electronics is used to accomplish systems-level functions. As part of the procedure, students develop an understanding of four systems concepts: rectification, filtering, energy efficiency, and reliability. In an optional procedure, students discover how the power output of a photovoltaic solar panel is related to its orientation. Together, the DC/AC inverter and the solar panel provide a platform for the instructor to create numerous follow-on experiments addressing renewable energy systems. 
Power Measurement (Energy): Along the lines of the previous module, this module is also motivated by the need to improve our electrical energy infrastructure. The focus is on distributed power measurement as a key aspect of making the grid 'smart'. The module considers tradeoffs of invasive and direct measurement of current and non-invasive (i.e., safe) but indirect current measurement using a split-core transformer current sensor. The video puts in context various aspects students may have covered in class, such voltage and current division, internal resistance requirements for voltmeters and ammeters, transformer functionality, and power factor correction. In the experiential component, students build their own current sensor that they can use to estimate the power draw of a variety of household devices. These local power measurements are put in the context of a layered view of the power system, where lower layers (appliances) interface to adjacent layers of the grid (household followed by neighborhood, etc.).

Inductive Heating (Energy): In this module direct (resistive) and indirect (inductive) heating are investigated. Resistive heating uses energy to generate dissipated power by forcing current through a resistive element. This will be a familiar concept to students that exemplifies one form of energy conversion, i.e., electrical to heat. A less familiar topic is inductive heating, in which a coil is used to generate an electromagnetic field that couples into a vessel made of ferrous material. Due to eddy current loss, the vessel itself becomes the heating source to its contents. For both heating methods, students will use a temperature-dependent resistor (thermistor) to measure temperature rise versus power. The concepts that are involved in this experiment include circuit elements (resistors and inductors) and circuit analysis (Ohm's law, power and energy). From a systems perspective, students will be asked to consider performance metrics such as efficiency, cost, safety and usability for applications such as heating liquids.

In Situ Sensing (Environment): The use of sensors by engineers and scientist is becoming ever more common. This module focuses on three common sensors: thermistors, photosensors, and strain gages. Using these three devices, the module covers topics ranging from thermal conductivity, photoresitivity, and resistance in wires. Students utilize these sensors to develop voltage divider and Wheatstone bridge circuits thereby enhancing their understanding of these textbook concepts. The videos detail real world applications where these devices are utilized and challenges the students to propose applications of these devices related to their own areas of study.

Remote Sensing (Environment): The module leverages the BalloonSat design which has been utilized by numerous universities and high schools ${ }^{12}$ to illustrate circuit concepts in the framework of environmental remote sensing. The University of Hawaii, in particular, has a decade of experience in launching BalloonSats for student projects, and the University of Vermont has incorporated them in outreach programs ${ }^{13}$. BalloonSats provide an attractive solution as an airborne platform that is inexpensive, autonomous, and readily deployable. Since BalloonSats can be constructed and launched in a few hours, they are an especially attractive candidate technology for rapid-response humanitarian assistance disaster relief. In the active learning component of this module, students build timing circuits for activating camera shutters using a 555-timer circuit and an onboard power supply. Students learn about resistors and capacitors, parallel and series configurations, Ohm's Law, circuit analysis, and AC signals. They also explore the systems-level perspective by designing the camera system to achieve mission goals while meeting size, weight, and power constraints, as well as learning survivability design in extreme environments. 
Evaluation of the ENFUSE Project

External evaluation of the ENFUSE project thus far has involved piloting the ENFUSE Bioelectrical Signals module in a four-week Summer 2013 Circuits course for non-majors at the University of Vermont and piloting five ENFUSE modules (Radiation from Wireless Devices, Power Measurement, DC/AC Inversion, Bioelectrical Signals, and Remote Sensing) in a semester-long Circuits course for majors and non-majors at the University of Hawaii during the Fall 2013 semester.

Our summative evaluation activities address the following overarching questions:

1. How does exposure to the ENFUSE modules impact student understanding of targeted learning outcomes and systems thinking?

2. How does exposure to the ENFUSE activities impact student interest and engagement in course-related topics?

3. Overall, what is the added value from incorporation of the ENFUSE modules into introductory electrical and computer engineering Circuits courses?

Additionally, evaluation activities are providing formative feedback from the Summer and Fall 2013 pilots to guide modifications to the materials and delivery. Formative feedback addresses student perceptions of the materials and faculty and teaching assistant perceptions of implementation. These include aspects of the materials and their delivery that supporting learning goals, and challenges to implementation.

Summer 2013 Bioelectrical Signals Module Pilot

A pilot Circuits course for non-majors was offered in the summer of 2013 at the University of Vermont in an accelerated, 4-week format. The course incorporated four (4) laboratory exercises, three of which were restructured versions of existing course experiments. Of the non-ENFUSE labs, Lab 1 looked at series and parallel resistances using digital multimeters, Lab 2 introduced students to the use of oscilloscopes, and Lab 3 looked at sinusoidal and transient responses of RL and RC circuits. For these labs, students collected data and then later turned in a report. The fourth exercise utilized the ENFUSE module on Bioelectrical Signals (from the Health thematic area) that included a laboratory exercise using a pulse sensor. This was the only ENFUSE module ready for piloting at the time the course was offered. Students were assigned to watch the videos in advance of the lab. During the lab, students utilized the instructional content that posed questions for which the students had to collect the appropriate data. At the end of the lab period, students handed in their solutions.

Ten students enrolled in the Summer 2013 pilot course. Students were sophomores entering their junior year in the following fall semester and included one female and nine males. Of those, seven were mechanical engineering majors and three were civil engineering majors. Students in the Summer 2013 pilot of the Bioelectrical Signals module completed feedback surveys on the ENFUSE module and also on three non-ENFUSE labs for comparison. The feedback surveys contained a mix of Likert-scale items and open-ended responses. Evaluators designed items to gather feedback on the ENFUSE module (or non-ENFUSE lab) quality, usefulness to student learning, and impacts on interest and understanding of the topic. 
On the Bioelectrical Signals module feedback survey, students indicated their level of agreement, on a scale of $1=$ strongly disagree to $5=$ strongly agree, to a series of questions about the quality and utility of the exercises as well as their impact on student interest in and understanding of the topic. Of the nine students who completed the survey, six (67\%) agreed and two (22\%) strongly agreed that the ENFUSE module increased their interest in the topic. Students reported that the module tied together interests in healthcare and mechanical engineering, with a biomedical focus, and promoted interest through hands-on pulse sensing application.

Students in the summer pilot also indicated that after participating, they had a good understanding of the key concepts covered in the Bioelectrical Signals module $(67 \%$ agreed and $22 \%$ strongly agreed). The overall quality of the ENFUSE module was noted to be significantly higher than the non-ENFUSE labs used for the course. Specifically, the ENFUSE module received $78 \%$ good and $22 \%$ excellent ratings while the existing (Non-ENFUSE) course exercises averaged $46 \%$ average and $50 \%$ good ratings. The ENFUSE module also received $100 \%$ affirmative response to the following question (as opposed to $66 \%$ for the non-ENFUSE exercises: Did the module present circuits topics in a way that was relevant to your interest? Students commented that students felt that what they learned in the Bioelectrical Signals module was applicable to "real world data collecting." As one commented, "We used a function that is similar to something we would see outside of class."

\section{Fall 2013 ENFUSE Module Pilot}

The Fall 2013 Circuits course at the University of Hawaii consisted of a single lecture section consisting of all participating students, and four separate laboratory sections offered at different times during the week. Two lab sections were randomly selected to participate in ENFUSE labs (treatment condition), while two sections used previously developed labs (control condition). Students in control sections completed the Non-ENFUSE labs presented in Appendix A. Students in the treatment lab sections completed the Non-ENFUSE laboratory exercises for Labs 1-5 during the first half of the semester and then participated in ENFUSE labs for the remainder of the course. The ENFUSE labs replaced Non-ENFUSE labs on capacitors, inductors, first-order circuits and second-order RL circuits, and partially replaced the lab on oscilloscopes.

Students in both treatment and control labs completed a pre/post attitude survey. The survey consisted of 16 Likert scale items again on a five-point scale ranging from $1=$ strongly disagree to 5 = strongly agree. The questions were grouped into statements regarding attitude toward circuits and course content (9 items) and understanding of course concepts ( 7 items). Students in the treatment (with ENFUSE) condition also completed ENFUSE module feedback surveys and non-ENFUSE lab feedback surveys for comparative purposes. The ENFUSE module feedback surveys and the lab feedback surveys were modified versions of the feedback survey completed in the Summer 2013 pilot and contained a mix of Likert-scale and open-ended items related to the ENFUSE module (or non-ENFUSE lab) quality, usefulness to learning, and impacts on interest and understanding of the topic.

The Fall 2013 study included 41 students in treatment (with ENFUSE) lab sections and 39 students in control sections. Of these, 29 students in ENFUSE lab sections and 33 students in non-ENFUSE lab sections gave informed consent to participate in the evaluation study and took 
both pre and post attitude surveys. Student demographics for students with consent and attitude surveys are presented in Table 3.

Table 3 - Student Demographics for Fall 2013 Pilot

\begin{tabular}{|c|c|c|c|c|}
\hline Condition & $\mathbf{N}$ & Gender & Academic Level & Major \\
\hline ENFUSE & 29 & $\begin{array}{c}\text { Female } 20.7 \% \\
\text { Male } 79.3 \%\end{array}$ & $\begin{array}{c}\text { Freshman } 0 \% \\
\text { Sophomore } 58.7 \% \\
\text { Junior } 34.5 \% \\
\text { Senior } 3.4 \% \\
\text { Graduate } 3.4 \%\end{array}$ & $\begin{array}{c}\text { Pre-Engineering 3.4\% } \\
\text { Electrical Engineering } 27.6 \% \\
\text { Mechanical Engineering } 48.3 \% \\
\text { Computer Engineering } 10.3 \% \\
\text { Civil Engineering } 6.9 \% \\
\text { Other (unspecified) } 3.4 \%\end{array}$ \\
\hline Non-ENFUSE & 36 & $\begin{array}{c}\text { Female } 12.1 \% \\
\text { Male } 87.9 \%\end{array}$ & $\begin{array}{c}\text { Freshman } 6.1 \% \\
\text { Sophomore } 57.6 \% \\
\text { Junior } 33.3 \% \\
\text { Senior } 3.0 \% \\
\text { Graduate } 0 \%\end{array}$ & $\begin{array}{c}\text { Pre-Engineering } 18.2 \% \\
\text { Electrical Engineering } 33.3 \% \\
\text { Mechanical Engineering } 30.3 \% \\
\text { Computer Engineering } 6.1 \% \\
\text { Bio Engineering } 9.1 \% \\
\text { Other (unspecified) } 3.0 \%\end{array}$ \\
\hline
\end{tabular}

\section{ENFUSE Module Feedback}

On the ENFUSE module feedback surveys, students indicated their level of agreement with the statement, "After completing the module, I have a good understanding of the key concepts covered" on a five-point scale ranging from $1=$ strongly disagree to $5=$ strongly agree. The majority of students agreed or strongly agreed that the Remote Sensing and Wireless Devices modules gave them a good understanding of the key content presented in the exercises $(70.3 \%$ and $58.3 \%$ respectively). Of the five modules, the Power Measurement module was most challenging for students; they felt that they did not gain an understanding of the content of the module (Table 4).

Table 4 - Level of Agreement with Statement About Understanding of Key Concepts by Module

\begin{tabular}{lcccccc}
\hline ENFUSE Module & $\begin{array}{c}\text { Strongly } \\
\text { Disagree }\end{array}$ & Disagree & $\begin{array}{c}\text { Neither Agree } \\
\text { nor Disagree }\end{array}$ & Agree & $\begin{array}{c}\text { Strongly } \\
\text { Agree }\end{array}$ & $\begin{array}{c}\text { Response } \\
\text { Mean }\end{array}$ \\
\hline Remote Sensing & $0 \%$ & $13.5 \%$ & $16.2 \%$ & $56.8 \%$ & $13.5 \%$ & 3.70 \\
\hline Wireless Devices & $4.9 \%$ & $4.9 \%$ & $31.7 \%$ & $51.2 \%$ & $7.3 \%$ & 3.51 \\
\hline Bioelectrical Signals & $12.0 \%$ & $12.0 \%$ & $28.0 \%$ & $32.0 \%$ & $16.0 \%$ & 3.28 \\
\hline DC/AC Inversion & $20.6 \%$ & $17.9 \%$ & $17.9 \%$ & $25.7 \%$ & $17.9 \%$ & 3.03 \\
\hline Power Measurement & $36.8 \%$ & $36.8 \%$ & $10.6 \%$ & $13.2 \%$ & $2.6 \%$ & 2.08 \\
\hline
\end{tabular}

Qualitative responses to a question asking what they found confusing about each module showed that for the Power Measurement module, the core content had not been covered in the lecture prior to the lab and students found the new material in the module difficult to understand without background knowledge. For example, students found the phasor notation and use of the equations particularly challenging.

On the ENFUSE module feedback surveys, students responded to a question about how each module helped them understand circuits as a tool in creating systems that we rely on. For all modules except the Power Measurement module, students indicated that the modules were useful in helping them to connect the content to real-world applications. For the Wireless Devices module, a typical student comment was, "Radiation from real life scenarios like the 
antenna helped me understand how circuits help such problems." For the DC/AC Inversion module a student stated, "It helped me learn how the circuits that are in everyday tools are used, like a power outlet, etc." Commenting on the Remote Sensing module, a typical comment was, "It gave examples of applications of the concepts used in this lab and how they affect our daily lives." While preliminary, these findings suggest that applications to real-world situations help students to understand the relationship of circuits concepts to broader systems. Across all ENFUSE labs, students found that the most useful aspects of the modules were (i) the opportunities for hands-on learning and (ii) the diagrams, pictures and videos for setting up the labs.

On the feedback surveys, students indicated their level of agreement with the statement, "The laboratory experiment increased my interest in the circuits concepts presented in the module." The majority of students (70.3\%) agreed or strongly agreed that the laboratory portion of the Remote Sensing module increased their interest in the topic. Slightly more than half $51.3 \%$ ) indicated that the $D C / A C$ Inversion lab increased their interest in the topic. The majority of students $(71 \%)$ disagreed or strongly disagreed that the Power Measurement lab increased their interest in the topic (Table 5).

Table 5 - Level of Agreement with Statement About Increased Interest in Module Topic

\begin{tabular}{lcccccc}
\hline ENFUSE Module & $\begin{array}{c}\text { Strongly } \\
\text { Disagree }\end{array}$ & Disagree & $\begin{array}{c}\text { Neither Agree } \\
\text { nor Disagree }\end{array}$ & Agree & $\begin{array}{c}\text { Strongly } \\
\text { Agree }\end{array}$ & $\begin{array}{c}\text { Response } \\
\text { Mean }\end{array}$ \\
\hline Remote Sensing & $8.1 \%$ & $2.7 \%$ & $18.9 \%$ & $54.1 \%$ & $16.2 \%$ & 3.68 \\
\hline Wireless Devices & $0.0 \%$ & $14.6 \%$ & $39.0 \%$ & $36.6 \%$ & $9.8 \%$ & 3.41 \\
\hline Bioelectrical Signals & $4.0 \%$ & $32.0 \%$ & $20.0 \%$ & $36.0 \%$ & $8.0 \%$ & 3.12 \\
\hline DC/AC Inversion & $17.9 \%$ & $15.4 \%$ & $15.4 \%$ & $41.0 \%$ & $10.3 \%$ & 3.10 \\
\hline Power Measurement & $44.7 \%$ & $26.3 \%$ & $21.1 \%$ & $7.9 \%$ & $0.0 \%$ & 1.92 \\
\hline
\end{tabular}

\section{Comparisons of Student Interest and Understanding}

To assess impact on student interest and engagement with course content, students in treatment and control lab sections completed a pre/post attitude survey. Students indicated their level of agreement with nine statements about their attitude toward course skills and topics. Items for this section of the survey included such statements as "I find the study of topics related to circuits interesting," and "The future benefits of studying circuits is worth the effort." The seven items related to students' beliefs in their understanding of course content included items such as "I understand how learning about circuits can be applied to real world problems," and "I feel confident in my ability to understand circuits concepts." Scores on the attitude section of the survey had a range of 9 (indicating strongly disagree on all items) to 45 (indicating strongly agree on all items). Scores on the beliefs about understanding section of the survey had a possible range of 7 to 35. Pre and post survey scores are presented in Figures 1 and 2 for students in treatment and control lab sections.

Attitudes toward course material and beliefs about understanding of course content were slightly higher for control students than for treatment students on the presurvey, although these differences were not statistically significant $(t(60)=0.76, p=0.45$ for attitude; $t(60)=0.45, p=$ 0.66 for understanding). Students in treatment sections who were exposed to both ENFUSE and Non-ENFUSE labs showed a decrease in attitude and in their beliefs about their understanding of course content over the course of the semester. The decrease for beliefs in their understanding of 
content was not statistically significant $(t(28)=-2.04, \mathrm{p}=0.51)$. The decrease in attitudes towards course material was statistically significant $(t(28)=-2.61, \mathrm{p}=0.01)$. Students in control (Non-ENFUSE only) lab sections showed a small increase in attitude and beliefs about their understanding of content, although these increases were not statistically significant.

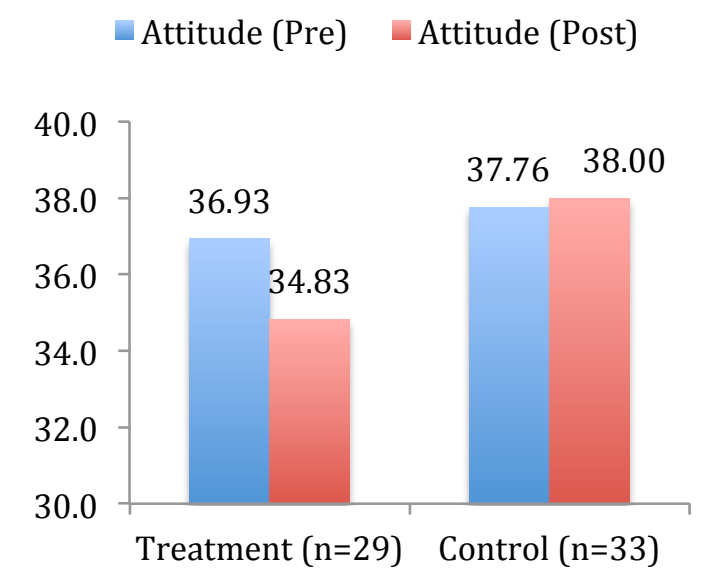

Figure 1. Attitudes towards course material.
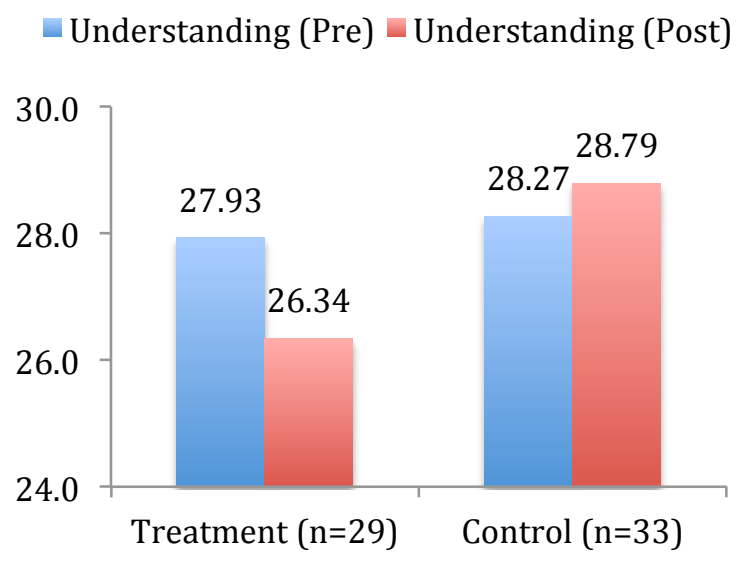

Figure 2. Beliefs about understanding content.

Students in the treatment sections rated the Non-ENFUSE labs higher than the ENFUSE labs for overall quality and utility (4.04 versus 3.20 on a five-point scale). In feedback surveys, students indicated that they were frustrated or confused when ENFUSE labs presented content they had not previously covered in the lecture portion of the course. Students also commented that at times, teaching assistants were not able to answer questions about the ENFUSE labs to their satisfaction. The faculty member teaching the course and the teaching assistants for the laboratory also commented on the lower levels of engagement for the ENFUSE labs.

The faculty member and teaching assistants noted that an important potential cause was the fact that lectures and laboratories were not coordinated, so that new content was presented in ENFUSE labs prior to their introduction in lecture materials. They also noted that students participating in the ENFUSE sections spent the first half of the semester participating in more traditional laboratory exercises and then switched mid-course to the ENFUSE labs that exposed them to more open-ended problems and that required a deeper level of systems thinking that was new to them. They commented that the switch in approaches between Non-ENFUSE labs and ENFUSE labs was challenging for students.

It should be noted that the Bioelectricity module implemented during Summer 2013 pilot at UVM received significantly higher evaluations than during this second pilot (e.g., understanding scores of $89 \%$ agree/strongly-agree vs. 48\%). In the Summer pilot, the Learning Module was assigned at the end of the term once all the book-based lecture material had been completed. Also, the lab instructor had co-developed the procedure and thus was intimately familiar with its content and motivation.

\section{Conclusion and Future Work}

In this work, we describe a project to develop systems thinking skills in students studying the foundational material in Circuits. As Circuits is core to most engineering programs and not just electrical engineering, the work could have far-reaching impact on future students. The 
effort leverages faculty at five institutions to develop curricular modules consisting of instructional videos and experiential learning exercises that integrate and provide context to the myriad of topics typically covered in a Circuits lecture. To date the material has been prototyped at two universities and two additional universities plan to utilize these materials in 2014.

While preliminary, the assessment data suggests a divergence between the positive attitudes and perceptions of students at the level of connecting circuits principles and concepts to their broader engineering and societal contexts, and the negative results for students' attitudes toward learning of specific circuits topics and self-assessment of their understanding of those topics. Specifically, in the Fall 2013 study, results for the ENFUSE approach were not a significant improvement over those for the traditional approach (Figures 1 and 2); especially noteworthy is the slight downward pre/post trend. At least two hypotheses emerge: (1) The sequencing of learning topics and the interplay of lecture and laboratory materials is extremely important, in that students need a foundation in the concepts and tools of circuits before hands-on exposure to their application in systems. (2) Students may become frustrated or intimidated when exposed to the breadth of knowledge needed to conceive and analyze systems, calling for exploration of the need for, and degree of, additional scaffolding and support. This latter aspect relates to improving the training of laboratory assistants who may also have limited exposure to real-world engineered systems. 


\section{Appendix A: Non-ENFUSE lab Descriptions at UH}

\begin{tabular}{|c|c|}
\hline Lab Title & Description \\
\hline Lab 1: Introduction & $\begin{array}{l}\text { Students learn about resistor color codes, how to use a breadboard to assemble a } \\
\text { simple circuit, and how to use a benchtop DC power supply. They also learn how } \\
\text { to use a digital multimeter to measure voltages, currents, and resistances in } \\
\text { circuits. }\end{array}$ \\
\hline $\begin{array}{l}\text { Lab 2: Series and Parallel } \\
\text { Circuits }\end{array}$ & $\begin{array}{l}\text { Students build series and parallel resistive circuits, and measure the voltages and } \\
\text { currents of the circuit elements. The measured results are used to verify } \\
\text { Kirchoff's voltage and current laws. }\end{array}$ \\
\hline Lab 3: Superposition Theorem & $\begin{array}{l}\text { Students verify the superposition theorem by building and measuring a linear } \\
\text { circuit containing more than one voltage source. Students will learn that } \\
\text { superposition can be applied to voltage and current, but not power. }\end{array}$ \\
\hline $\begin{array}{l}\text { Lab 4: Thevenin Equivalent } \\
\text { Circuits }\end{array}$ & $\begin{array}{l}\text { Students will measure the Thévenin voltage and Thévenin resistance of a linear } \\
\text { circuit, and will reduce it to the Thévenin equivalent circuit. The equivalent } \\
\text { circuit will be used to verify Thévenin's theorem. }\end{array}$ \\
\hline Lab 5: Operational Amplifiers & $\begin{array}{l}\text { Students build three types of DC operational amplifier circuits (voltage follower, } \\
\text { inverting amplifier, non-inverting amplifier), and measure the output verify } \\
\text { correct operation. }\end{array}$ \\
\hline $\begin{array}{l}\text { Lab 6: Oscilloscopes / AC } \\
\text { signals }\end{array}$ & $\begin{array}{l}\text { Students learn how to use the function generator to create AC waveforms, and } \\
\text { how to measure the signals using an oscilloscope. Students also analyze the AC } \\
\text { signals to quantify period, frequency, amplitude, and rms values. }\end{array}$ \\
\hline Lab 7: Capacitors & $\begin{array}{l}\text { Students observe the voltage and current relationship in a capacitor, determine } \\
\text { the capacitance from that relationship, and evaluate the instantaneous transfer of } \\
\text { energy and power. }\end{array}$ \\
\hline Lab 8: Inductors & $\begin{array}{l}\text { Students observe the voltage and current relationship in an inductor, determine } \\
\text { the inductance from that relationship, and evaluate the instantaneous transfer of } \\
\text { energy and power. }\end{array}$ \\
\hline Lab 9: First-order circuits & Students build, measure, and analyze a first-order RC circuit. \\
\hline $\begin{array}{l}\text { Lab 10: Second-order RLC } \\
\text { circuits }\end{array}$ & $\begin{array}{l}\text { Students build and measure a second-order series RLC circuit. The step response } \\
\text { for the circuit is measured and analyzed for over-damped, critically damped, and } \\
\text { under-damped cases. }\end{array}$ \\
\hline
\end{tabular}

\section{Bibliography}

1 The National Academy of Engineering, Grand Challenges for Engineering, information online: www.engineeringchallenges.org (accessed: May 23, 2011).

2 Integration - including transdisciplinary and interdisciplinary science [Online]. Available: http://learningforsustainability.net/research/interdisciplinary.php. [Accessed: 24-May-2011].

${ }^{3}$ J. T. Klein, Evaluation of interdisciplinary and transdisciplinary research: a literature review, American Journal of Preventive Medicine, vol. 35, no. 2, p. S116-S123, 2008.

${ }^{4}$ P. Sharp, et al, The Third Revolution: The Convergence of the Life Sciences, Physical Sciences, and Engineering, MIT Report No. 10-11-0527.

${ }^{5}$ The National Academy of Engineering, The Engineer of 2020: Visions of Engineering in the New Century, The National Academics Press, 2004. 
${ }^{6}$ National Research Council, Improving undergraduate instruction in science, technology, engineering and mathematics: Report of a Workshop. National Academy Press, 2003. Retrieved from http://www.nap.edu/catalog.php?record_id=10711.

${ }^{7}$ J. Bransford, N. Vye, and H. Bateman, Creating high quality learning environments: Guidelines from research on how people learn, In P. Graham and N. Stacey (eds), The knowledge economy and postsecondary education: Report of a workshop. National Academies Press, 2002.

${ }^{8} \mathrm{~J}$. Bransford, A. Brown, and R. Cocking, How people learn: Brain, mind, experience and school, National Academy Press, 2000.

${ }^{9}$ S. Zekevat, C. Sandu, G. Archer and K. Hungwe, An evaluation of the teaching approach for the interdisciplinary course electrical engineering for non-majors, Proceedings of the 2004 Annual ASEE Conference \& Exposition, Salt Lake City, Utah, June 20-24, 2004.

${ }^{10}$ L. Deslauriers, E. Schelew and C. Wieman, Improved learning in a large-enrollment physics class, Science 332, $862,2011$.

${ }^{11}$ J. Frolik, P. Flikkema, T. Weller, C. Haden, W. Shiroma and R. Franklin, Leveraging multi-university collaboration to develop portable and adaptable online course content, ASEE Advances in Engineering Education (online), Vol. 3, No.3, Winter 2013.

${ }^{12}$ Colorado Space Grant Consortium, Starting Student Space Hardware Programs: A How To Workshop (20022006), information online: http://spacegrant.colorado.edu/COSGC_Projects/studentsat (accessed May 15, 2011).

${ }^{13}$ J. Frolik and M. Fortney, A low-cost wireless platform for first year, interdisciplinary projects, IEEE Trans. Education, Vol. 49, No. 1, February 2006. 